\title{
The endosonographic appearance of a type-A choledochocele
}

\section{Fateh Bazerbachi ${ }^{a}$, Kavel H. Visrodiaa ${ }^{\text {, Georgios Mavrogenis }}{ }^{b}$, Mark D. Topazianc}

Massachusetts General Hospital, Boston, USA; Mediterraneo Hospital, Athens, Greece; Mayo Clinic, Rochester, Minnesota, USA

An 83-year-old woman with a history of idiopathic pancreatitis 20 years previously presented to the pancreaticobiliary clinic for evaluation of a $1.5-\mathrm{cm}$ periampullary mass. The mass was incidentally detected on a computed tomography scan (Fig. 1) obtained during an episode of diverticulitis that resolved with medical treatment. Endoscopic ultrasound (EUS) revealed a cystic ampullary lesion that communicated with the common bile duct (Fig. 2C). The pancreatic duct was seen to drain separately into the major papilla. Endoscopically, the subepithelial mass was proximal to the major papilla orifice (Fig. 2 A,B). The patient was diagnosed with type-A choledochocele and was referred back to the clinic to discuss potential therapy options.

Choledochoceles are cystic expansions of the intraduodenal segment of the main bile duct and are classified according to their location compared with the major papilla [1]. Type-A choledochoceles are cystic expansions of a portion of the intra-ampullary bile duct and can be seen as submucosal bulges proximal to the major papilla. The bile duct drains into the choledochocele, which drains to the duodenum via the ampullary orifice. Conversely, a type-B choledochocele is a diverticulum of the intra-ampullary common channel and can be seen distal to the major papilla. Both types of choledochoceles can lead to biliary obstruction, pancreatitis, nonspecific gastrointestinal symptoms or (rarely) malignancy. Treatment should relieve ductal obstruction, remove associated stones or sludge, and assess for dysplasia, whether by resection or drainage into the bowel lumen via endoscopic or surgical techniques.

Choledochoceles can be misdiagnosed as other periampullary tumors, although endoscopy delineates the

\footnotetext{
${ }^{a}$ Division of Gastroenterology, Interventional Endoscopy Program, Massachusetts General Hospital, Boston, Massachusetts, USA (Fateh Bazerbachi, Kavel H. Visrodia); ' Department of Gastroenterology, Mediterraneo Hospital, Athens, Greece (Georgios Mavrogenis); 'Division of Gastroenterology and Hepatology, Mayo Clinic School of Medicine, 200 First Street SW, Rochester, MN, USA (Mark D. Topazian)

\section{Conflict of Interest: None}

Correspondence to: Fateh Bazerbachi, MD, Division of Gastroenterology, Interventional Endoscopy Program, Massachusetts General Hospital, 55 Fruit Street

Blake 4 rm 453D, Boston, MA 02114, USA,

e-mail: fbazerbachi@mgh.harvard.edu
}

Received 11 October 2019; accepted 28 October 2019; published online 21 November 2019

DOI: https://doi.org/10.20524/aog.2019.0433

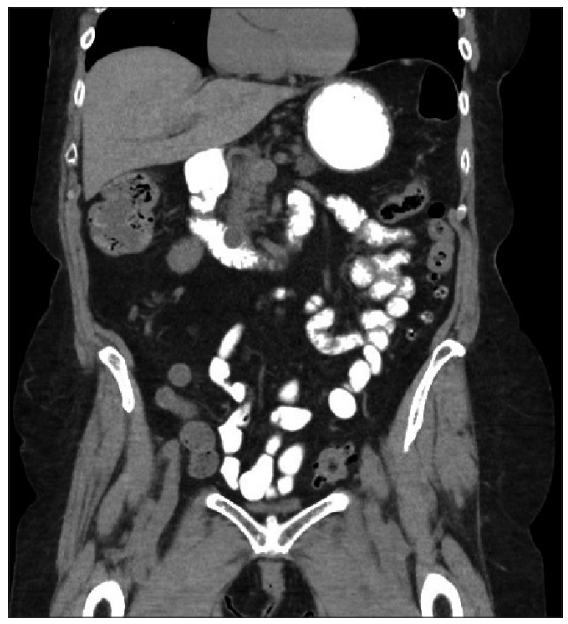

Figure 1 Cross-sectional computed tomography image of the incidentally-identified periampullary mass on coronal view

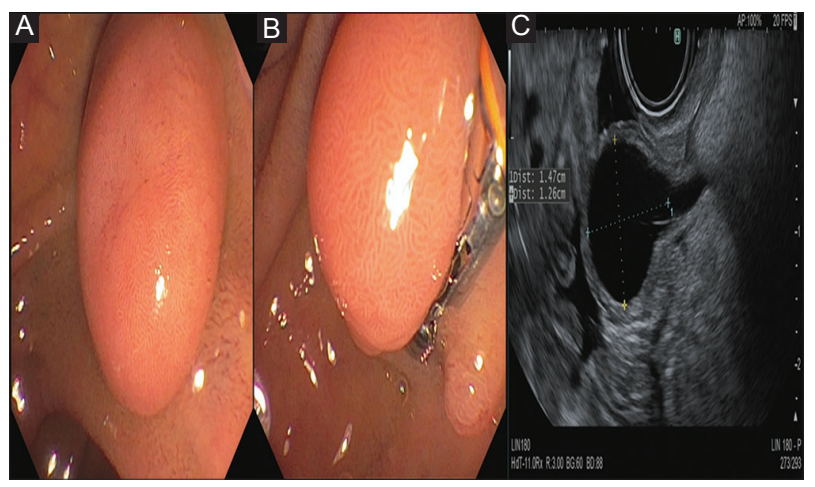

Figure 2 Endoscopic view of type-A choledochocele showing as a submucosal mass (A), with a proximal relation to the major papilla (B). Endosonographic view of the choledochocele showing its continuity with the common bile duct, as seen from the second portion of the duodenum (C)

submucosal nature of these lesions. EUS demonstrates the cystic nature of the lesion, its relationship to the periampullary ducts, and distinguishes choledochoceles from duodenal duplications (which typically involve deeper layers of the duodenal wall).

\section{Reference}

1. Law R, Topazian M. Diagnosis and treatment of choledochoceles. Clin Gastroenterol Hepatol 2014;12:196-203. 